\title{
Corrosion assessment of structural components using electro mechanical impedance
}

\author{
N. Naga Sai Pravallika ${ }^{l}$, Dr. V. Mallikarjuna Reddy ${ }^{2}$ and Dr. B. Siva Konda Reddy ${ }^{3}$. \\ ${ }^{1}$ M.Tech Scholar, Civil Engineering Department, GRIET, Hyderabad, Telangana, India. \\ ${ }^{2}$ Professor \&Head, Civil Engineering Department, GRIET, Hyderabad, Telangana, India. \\ ${ }^{3}$ Associate Professor, Civil Engineering Department, JNTUH, Hyderabad, Telangana, India.
}

\begin{abstract}
Rapid innovation in interdisciplinary technology emphasized the data acquisition system to evaluate the structural integrity by combining with advance sensing techniques. These smart sensors with impedance methodology has shown an excellent potential in assessing the structural health condition and provided an alternative to many sophisticated Non destructive monitoring systems. The sensitivity of electro mechanical impedance technique in detecting local incipient damages is enhanced with piezoelectric mechanism of lead zirconate titanate materials and with conductance signatures these materials can determine the dynamic variations in structural properties more effectively. In the present work numerical finite element analysis is conducted on simply supported RCC beam in Abaqus software with reinforcement subjected to corrosion in five stages with different reduction rates and coupled with piezoelectric transducers along the length to implement the impedance strategy. These surface bonded piezoelectric patches are electrically excited with an external voltage under specific frequency range to conduct linear perturbation harmonic analysis and the output conductance responses of healthy and corroded beams from different sensor locations are captured and compared. The peak shifting nature of signature pattern will serve as an indicator to diagnose the corrosion severity and propagation in structural components. The simulation results of proposed impedance technique showed the feasibility of employing piezoelectric materials to identify corrosion activity in structural members with electromechanical conductivity signatures.

Keywords: Electro Mechanical impedance, Conductance signatures, Piezoelectric transducer, Couple field FEA, Electrochemical steel corrosion.
\end{abstract}

\section{Introduction}

Corrosion assessment in reinforced concrete structures has become the focus of research for the past two decades due to its intricate and complex mechanism [1]. The variations in humidity and diurnal temperatures render the steel to undergo corrosion causing premature structural deterioration [2]. The initiation and propagation of corrosion in reinforcement depends on the availability of moisture content, depassivating ions, concrete and steel grade, protective layer thickness and environmental conditions [3]. The electrochemical process of intrusion of chloride, carbon dioxide is a slow dynamic nonlinear mechanism that results in the formation of rust of larger volume at the interface. This expansive nature of the product generates radial stresses that lead to loss of bond between concrete and steel, steel embrittlement, spalling, cracking and excessive deflections [4]. Due to degradation of the passive layer, the load carrying capacity and ultimate strength of the structure are reduced and causes sudden collapse [5]. Therefore performance evaluation in terms of safety and integrity has to be carried out to determine the residual service life of the structure [6]. Hence the health condition of the structural components has to be monitored in every stage of lifecycle to reduce the detrimental effects.

This led to the development of advance techniques and analytical concepts in Structural Health Monitoring for evaluating the damage severity [7]. With the evolution of Nondestructive methods such as Electro chemical half cell potential method, Linear polarization resistance method, Ground penetrating radar test, Infrared thermography, 
Coverometer, Acoustic emissions, the in situ structural inspection is facilitated without destroying the elements [8]. But detailed investigation is not possible with these quality assurance tests as they suffer with distinct limitations such as lack of reliability, portability, trained technicians, costly equipment, complicated mechanism and electromagnetic interferences. It is imperative to choose appropriate monitoring system whose diagnostic analysis can provide complete information regarding damage initiation, proliferation, hairline cracks and impending failure [9]. Rapid advancement in Electronics and Information technology improved data acquisition systems and enhanced their application in Civil engineering [10]. The technical improvements in instrumentation and sensors enabled them to perform efficient maintenance operations [11]. Without human interference, these automated sensors are capable of monitoring the structural health condition continuously from any distant areas.

A variety of sensors like plastic optical fibers [12], accelerometers, ultrasonic [13], moisture, temperature, electro chemical sensors etc are available to measure the material physical and chemical properties. Among these sensors piezoelectric materials have gained a lot of significance due to their special piezoelectric property of converting electrical polarization energy into mechanical strain energy [14,15]. This conversion is a reversible process and was first discovered by French Scientists Pierre and Jacques Curie in 1880 [16]. The inverse effect of piezoelectricity enabled them to act as sensors, actuators, transistors and this optimistic function helps to perform critical EMI analysis [17]. Electro Mechanical Impedance is a local technique which utilizes high frequency waves like ultrasonic, acoustic for carrying analysis which is virtually not possible with traditional modal tests [18]. Intense research is carried out to predict the inhomogeneity of the structure with EMI method by exciting the highly sensitive piezoelectric sensors $[19,20]$. These materials on application of external voltage can detect the dynamic changes in a structure like mode shapes, damping factor and natural frequencies with electrical conductance signatures which are the real part of electro mechanical admittance signatures [21]. The conductivity signatures with its peak shifting character has emerged as the most reliable and inexpensive technique for monitoring the health status.

Moreover with Impedance based finite element modeling, the complexity involved in analyzing complicated geometry structures is simplified in Numerical methods by offering solutions which are relatively closer to the experimental results [22]. Non linear analysis can be performed in Abaqus CAE software by coupling structural and electrical fields with piezoelectric impedance technique [23]. This software is capable of processing and evaluating the structural models with good visual rendering process.

\section{Numerical study}

In the present study, a smart simply supported concrete beam coupled with piezoelectric transducers is considered to perform finite element modeling in Abaqus Simulia. Corrosion is induced in the beam from one end by reducing the cross sectional area of reinforcement. Three damage cases are considered for analysis by assuming that corrosion propagates at a distance of one fourth length, half length and three fourth length of the beam from left to right end as shown in figure 1 . In each case, the reinforced beam undergoes corrosion in five stages. These stages indicate $20 \%, 40 \%, 60 \%, 80 \%$ and $100 \%$ reduction in the diameter of bars and stirrups which is shown in Table 1. Numerical simulations are conducted on healthy and damaged beams by impedance based couple field analysis and conductivity signatures are recorded from all the cases with surface bonded piezoelectric patches placed at three different locations. These captured responses are compared with each other to anticipate the corrosion activity.

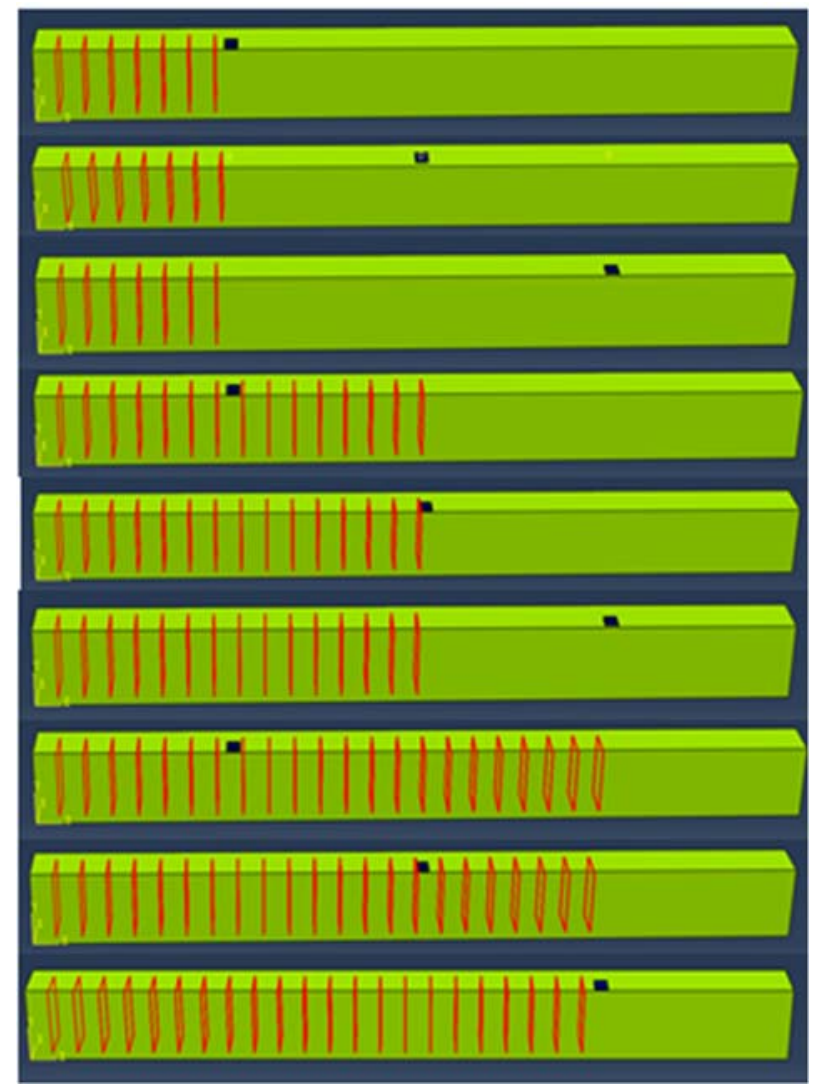

Fig.1. Corroded beams with piezoelectric at various locations Table 1. Simply supported beam with various damage cases and piezoelectric positions. 


\subsection{Geometry and Properties}

Initially, a Simply supported healthy concrete beam of length $6 \mathrm{~m}$ is modeled in part module as a three dimensional 8 noded solid element with a cross section of $300 \mathrm{~mm} \times 450 \mathrm{~mm}$. Reinforcement is provided to the concrete element with 3-16Ø main bars, 2-12Ø hanger bars and $200 \mathrm{~mm}$ spacing 2 legged $8 \varnothing$ stirrups by modeling as 2 noded beam elements. The steel rebars are embedded into the concrete section in interaction module with a clear cover of $30 \mathrm{~mm}$. For the present numerical study, a piezoelectric patch of size $50 \mathrm{~mm} \times 50 \mathrm{~mm} \times 20 \mathrm{~mm}$ is designed as a $3 \mathrm{D}$ couple field element having six degrees of freedom at each node. The piezoelectric sensor and the reinforced concrete sections are assigned with material properties that are mentioned in Table 2 and Table 3. The contact between the PZT and host structure is accomplished using a tie constraint. After assembling, meshing of geometry is done independently by selecting suitable element type. The beam and patch are discretized with an approximate global mesh size of $0.05 \mathrm{~m}$ and $0.01 \mathrm{~m}$ in Mesh control module.

Table 2. Piezoelectric material properties

\begin{tabular}{|l|cccccc|}
\hline $\begin{array}{l}\text { Density } \\
\left(\mathrm{kg} / \mathrm{m}^{3}\right)\end{array}$ & 7500 & & & & & \\
\hline $\begin{array}{l}\text { Dielectric } \\
\text { constant } \\
\left(10^{-9}\right.\end{array}$ & D11 & D22 & D33 & & & \\
Farad/m) & 6.5 & 6.5 & 6.5 & & & \\
\hline $\begin{array}{l}\text { Piezoelectric } \\
\text { constant } \\
\left(10^{-10} \text { C/N) }\right.\end{array}$ & {$\left[\begin{array}{ccccccc}0 & 0 & 0 & 0 & 12.7 & 0 \\
& & 0 & 0 & 0 & 0 & 12.7 \\
& & & & & & \\
-5.2 & -5.2 & 15.1 & 0 & 0 & 0\end{array}\right]$} \\
\hline $\begin{array}{l}\text { Elastic } \\
\text { Modulus } \\
\left(10^{10} \text { Pascal }\right)\end{array}$ & {$\left[\begin{array}{ccccccc}13.9 & 7.8 & 7.4 & 0 & 0 & 0 \\
0 & 13.9 & 7.4 & 0 & 0 & 0 \\
0 & 0 & 11.5 & 0 & 0 & 0 \\
0 & 0 & 0 & 3.05 & 0 & 0 \\
0 & 0 & 0 & 0 & 2.56 & 0 \\
0 & 0 & 0 & 0 & 0 & 3.05\end{array}\right]$} \\
\hline
\end{tabular}

Table 3. Reinforced concrete section properties

\begin{tabular}{|l|l|l|}
\hline Material type & Concrete & Steel \\
\hline Grade & $M_{25}$ & Fe 415 \\
\hline $\begin{array}{l}\text { Young's } \\
\text { Modulus }(\mathrm{Pa})\end{array}$ & $2.5 \times 10^{10}$ & $2.1 \times 10^{11}$ \\
\hline Density $\left(\mathrm{kg} / \mathrm{m}^{3}\right)$ & 2400 & 7850 \\
\hline Poisson's ratio & 0.15 & 0.3 \\
\hline
\end{tabular}

\begin{tabular}{|c|c|c|c|}
\hline $\begin{array}{l}\text { Patch } \\
\text { Location }\end{array}$ & \begin{tabular}{|c|} 
Location 1: \\
$1.5 \mathrm{~m}$ from left \\
support
\end{tabular} & $\begin{array}{l}\text { Location 2: } \\
\text { 3.0m from left } \\
\text { support }\end{array}$ & \begin{tabular}{|c|} 
Location 3: \\
$4.5 \mathrm{~m}$ from left \\
support
\end{tabular} \\
\hline $\begin{array}{c}\text { Corroded } \\
\text { Cases }\end{array}$ & $\begin{array}{c}\text { Extent of } \\
\text { damage from } \\
\text { left end }\end{array}$ & $\begin{array}{l}\text { Percentage } \\
\text { reduction in } \\
\text { diameter of } \\
\text { reinforcement }\end{array}$ & Representation \\
\hline \multirow{5}{*}{ Case 1} & \multirow{5}{*}{$1.5 \mathrm{~m}$} & $20 \%$ & $1 \mathrm{~A}$ \\
\hline & & $40 \%$ & 1B \\
\hline & & $60 \%$ & $1 \mathrm{C}$ \\
\hline & & $80 \%$ & 1D \\
\hline & & $100 \%$ & $1 \mathrm{E}$ \\
\hline \multirow{5}{*}{ Case 2} & \multirow{5}{*}{$3 \mathrm{~m}$} & $20 \%$ & $2 \mathrm{~A}$ \\
\hline & & $40 \%$ & $2 B$ \\
\hline & & $60 \%$ & $2 \mathrm{C}$ \\
\hline & & $80 \%$ & $2 \mathrm{D}$ \\
\hline & & $100 \%$ & $2 \mathrm{E}$ \\
\hline \multirow{5}{*}{ Case 3} & \multirow{5}{*}{$4.5 \mathrm{~m}$} & $20 \%$ & $3 \mathrm{~A}$ \\
\hline & & $40 \%$ & $3 B$ \\
\hline & & $60 \%$ & $3 C$ \\
\hline & & $80 \%$ & $3 D$ \\
\hline & & $100 \%$ & $3 \mathrm{E}$ \\
\hline
\end{tabular}

\subsection{Loads and analysis}

Boundary conditions are assigned to the beam in the initial step module by selecting pinned support conditions at both the ends. All the member analysis will come under next steps of step module. Linear perturbation analysis is carried on healthy and different corroded beams in step-1 and dynamic responses are obtained in the form of mode shapes and natural frequencies. In Step-2 harmonic analysis is conducted by applying an external voltage of $1 \mathrm{~V}$ on the top surface of the piezoelectric patch and the beam is excited in the frequency range of $1-200 \mathrm{~Hz}$ with sub step interval of 100 to extract electrical conductivity signatures.

\section{Results and Discussions 3.1 Modal analysis}

The natural frequencies corresponding to first five mode shapes are considered for all the cases by conducting frequency analysis using Bloc Lanczos method. For a fixed patch location the natural frequencies of different damage stages A, B, C, D \& E are extracted and compared with healthy state natural frequency as shown in Table 4. It is observed that as the percentage of corrosion in beams is increased, the natural frequencies got reduced. The decrease in natural frequency $\left(\omega_{n}=\sqrt{k / m}\right)$ of the beams shows that the percentage reduction in stiffness is more than percentage reduction of mass in corroded beams. The natural frequency remains the same in all the cases for various patch locations.

\subsection{Harmonic analysis}

The Steady state responses of the corrosion induced beams are determined by performing harmonic 
analysis in the frequency range of $1-200 \mathrm{~Hz}$. An external

In first case, one fourth length is considered to

\begin{tabular}{|l|l|l|l|l|l|c|}
\hline Case & Mode no & \multicolumn{5}{|c|}{ Natural Frequency(Hz) } \\
\cline { 3 - 7 } & & A (20\%) & B (40\%) & C (60\%) & D (80\%) & E (100\%) \\
\hline Case1 & 1 & 15.343 & 15.295 & 15.252 & 15.229 & 15.182 \\
& 2 & 25.957 & 25.938 & 25.912 & 25.879 & 25.862 \\
& 3 & 51.639 & 51.547 & 51.469 & 51.414 & 51.394 \\
& 4 & 65.309 & 65.078 & 64.901 & 64.786 & 64.747 \\
& 5 & 66.569 & 66.474 & 66.282 & 65.938 & 65.743 \\
\hline Case2 & 1 & 15.256 & 15.228 & 15.203 & 15.185 & 15.179 \\
& 2 & 24.942 & 24.921 & 24.915 & 24.873 & 24.857 \\
& 3 & 51.594 & 51.411 & 51.325 & 51.275 & 51.257 \\
& 4 & 65.154 & 64.874 & 64.657 & 64.524 & 64.479 \\
& 5 & 66.312 & 66.191 & 65.871 & 65.756 & 65.649 \\
\hline
\end{tabular}

electric field is generated by applying a voltage of $1 \mathrm{~V}$ on the top surface of piezoelectric patch with beam attached to the bottom layer. This electrical potential will actuate the beam to produce EMI signatures as response. For analysis conductance signatures that are real part of admittance signatures are considered to identify the corrosion. The signatures from healthy and different damage conditions are captured in $20-30 \mathrm{~Hz}$ frequency range as more number of resonant peaks is observed in this range with 30 sub step interval by placing the sensor at three different locations on the beam. be corroded with different mass reduction rates by decreasing the steel diameter from $20 \%$ to $100 \%$. In each stage, the electrical conductance signatures are captured from the piezoelectric patches placed at a distance of $1.5 \mathrm{~m}$, $3 \mathrm{~m} \& 4.5 \mathrm{~m}$ from left end and compared with healthy condition as shown in Figures 2, 3 and 4. 


\begin{tabular}{|l|l|l|l|l|l|l|}
\hline Case3 & 1 & 15.232 & 15.217 & 15.193 & 15.177 & 15.159 \\
& 2 & 24.911 & 24.812 & 24.771 & 24.728 & 24.712 \\
& 3 & 51.507 & 51.413 & 51.317 & 51.255 & 51.232 \\
& 4 & 65.116 & 64.766 & 64.494 & 64.322 & 64.263 \\
& 5 & 66.182 & 65.889 & 65.671 & 65.516 & 65.458 \\
\hline
\end{tabular}

Table 4. Mode shapes and Natural frequencies of Corroded beams in different cases

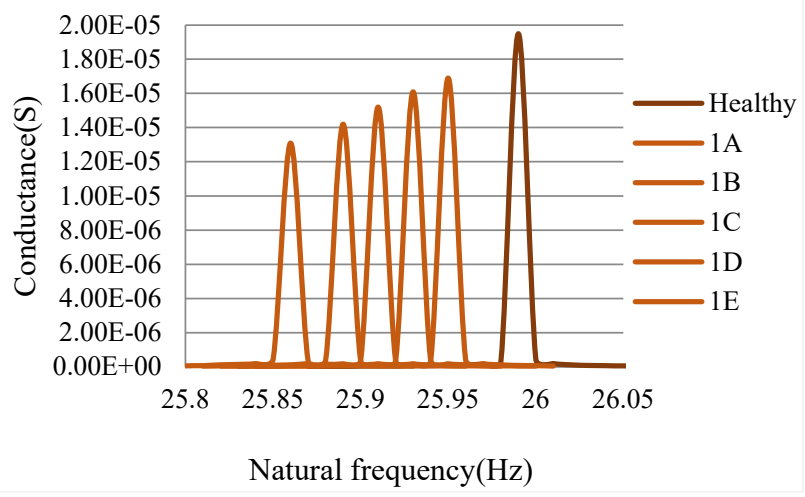

Fig.2. Conductance Signatures for $1^{\text {st }}$ Case at location 1

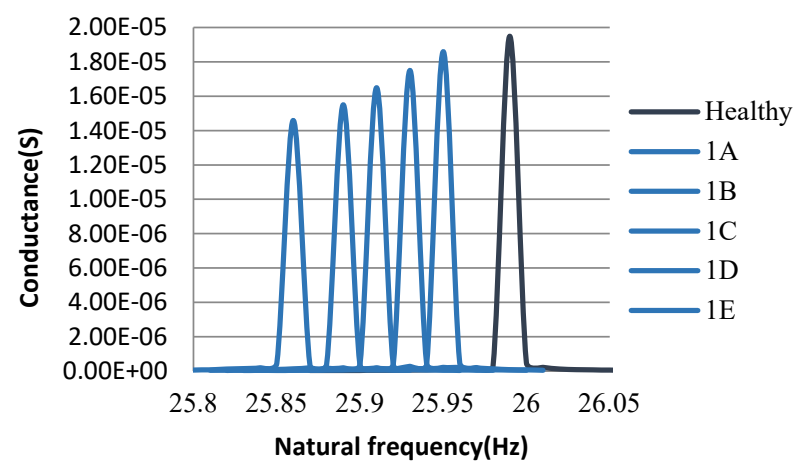

Fig.3. Conductance Signatures for $1^{\text {st }}$ Case at location 2

Fig.4. Conductance Signatures for $1^{\text {st }}$ Case at location 3

In second case, half length of the beam is considered to undergo corrosion with different diameter reduction rates and in each stage the conductance signatures from different piezoelectric patches placed at a distance of $1.5 \mathrm{~m}$, $3 \mathrm{~m}$ and $4.5 \mathrm{~m}$ from left end are captured. The corroded beams are compared with healthy condition as shown in Figures 5, 6 and 7. In third case, three fourth length of beam is considered to undergo corrosion and signatures are plotted and compared with healthy beam as shown in Figures 8,9 and 10.
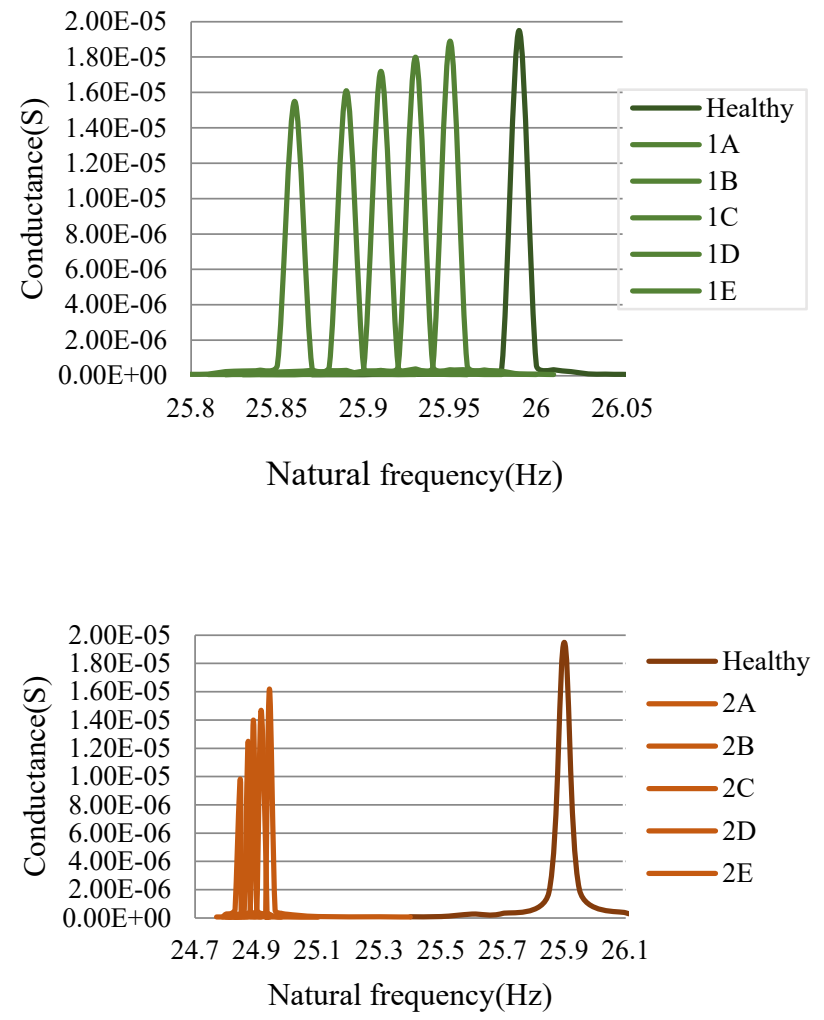

Fig.5. Conductance Signatures for $2^{\text {nd }}$ Case at location 1

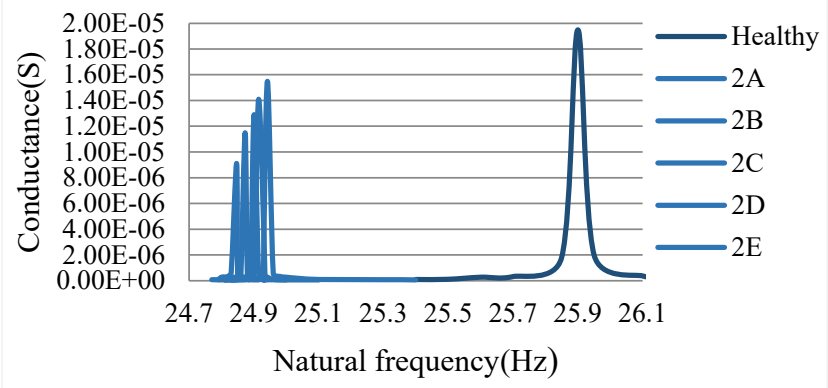

Fig.6. Conductance Signatures for $2^{\text {nd }}$ Case at location 2 


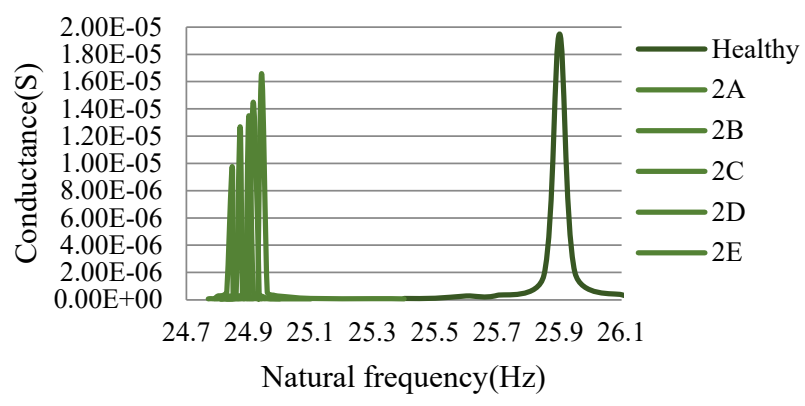

Fig.7. Conductance Signatures for $2^{\text {nd }}$ Case at location 3

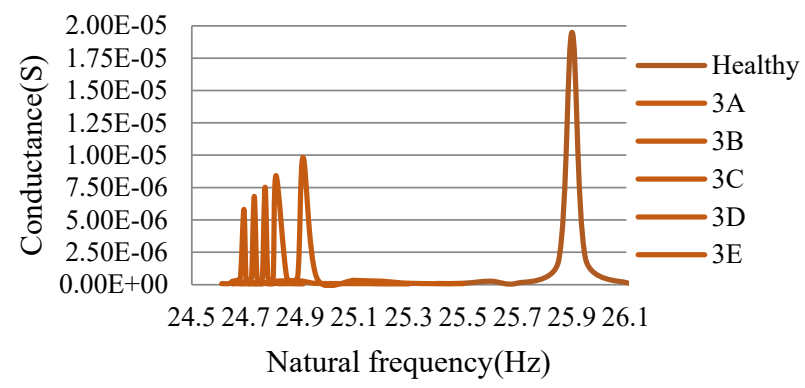

Fig.8. Conductance Signatures for $3^{\text {rd }}$ Case at location 1

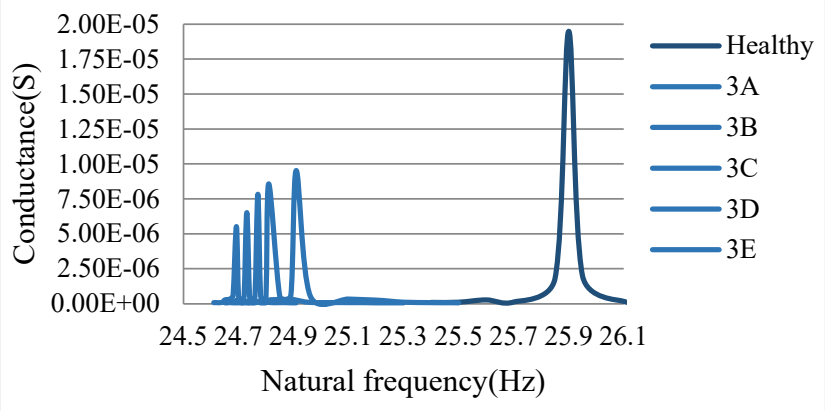

Fig.9. Conductance Signatures for $3^{\text {rd }}$ Case at location 2

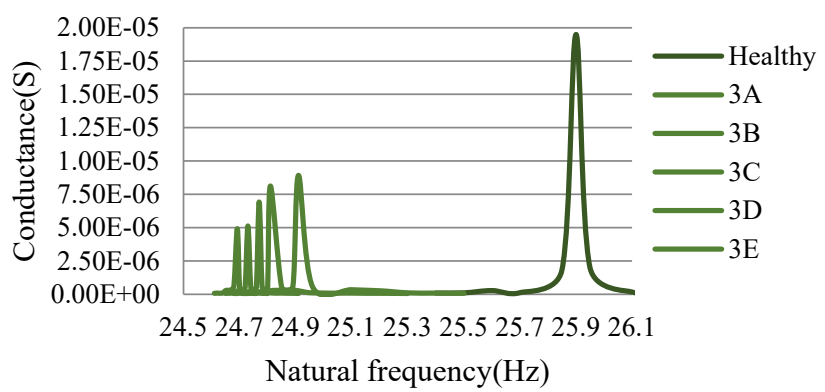

Fig.10. Conductance Signatures for $3^{\text {rd }}$ Case at location 3
From the plotted graphs, it is observed that as the percentage of corrosion activity is increased from Stage A to Stage E, the peak values of the conductivity signatures got reduced. The reduction in natural frequencies due to increase of corroded length from $1.5 \mathrm{~m}$ to $4.5 \mathrm{~m}$ shifted the signature peaks to left side. By comparing the Electro Mechanical signatures from surface bonded piezoelectric transducers at various geometric positions it is noticed that the patch which is located near to the corroded area showed a resonant peak of magnitude relatively lower than the other two.

\section{Conclusions}

Based on the numerical investigations and simulation results the following conclusions are documented:

1. The variation in dynamic properties with natural frequency decrement will indicate the damage presence in a structure.

2. The severity of corrosion is revealed with downward shift in peak values of captured electrical conductance signatures of harmonic analysis.

3. Remarkable aspect of this technique is the possibility to predict damage geometrical location by comparing the responses of various sensors incorporated at different locations.

4. It is concluded that with Abaqus software critical couple field numerical analysis can be performed by bringing good coordination with the host structure and smart system.

5. This method of monitoring with piezoelectric sensors offered a relatively inexpensive and reliable technique to anticipate the corrosion initiiation with better robustness.

\section{References}

1. C. Li Qing (2004), Reliability based service life prediction of corrosion affected concrete structures, Journal of Structural Engineering, Vol. 130, No. 10, pp. 1570-1577, (2004).

2. A. K. Azad, S. Ahmad and S. A. Azher, Residual strength of corrosion-damaged reinforced concrete beams, ACI materials journal, Vol. 104, No. 1, pp. 40, (2007).

3. W. Zhu, R. François, C. Zhang and D. Zhang, Propagation of corrosion-induced cracks of the RC beam exposed to marine environment under sustained load for a period of 26 years, Cement and Concrete Research, Vol. 103, pp. 66-76, (2018).

4. J. Cao, L. Liu and S. Zhao, Relationship between Corrosion of Reinforcement and Surface Cracking Width in Concrete, Advances in Civil Engineering, (2020).

5. J. Chen, P. Li, G. Song and Z. Ren, Piezo-based wireless sensor network for early-age concrete 
strength monitoring, Optik, Vol. 127, No. 5, pp. 29832987, (2016).

6. W. Slika and G. Saad, An Ensemble Kalman Filter approach for service life prediction of reinforced concrete structures subject to chloride-induced corrosion, Construction and Building Materials, Vol. 115, pp. 132-142, (2016).

7. M. Abdulkarem, K. Samsudin, F. Z. Rokhani and M. F. Rasid, Wireless sensor network for structural health monitoring: A contemporary review of technologies, challenges, and future direction, Structural Health Monitoring, Vol. 19, No. 3, pp. 693-735, (2020).

8. C. Scuro, P. F. Sciammarella, F. Lamonaca, R. S. Olivito and D. L. Carni, IoT for structural health monitoring, IEEE Instrumentation \& Measurement Magazine, Vol. 21, No. 6, pp. 4-14, (2018).

9. S. H. Park, J. H. Yi, C. B. Yun and Y. R. Roh, Impedance-based damage detection for civil infrastructures, KSCE Journal of Civil Engineering, Vol. 8, No. 4, pp. 425-433, (2004).

10. A. Abdelgawad and K. Yelamarthi, Structural health monitoring: Internet of things application, 2016 IEEE 59th International Midwest Symposium on Circuits and Systems (MWSCAS), IEEE, pp. 1-4, (2016).

11. Q. Zhang and Z. Xiong, Crack detection of reinforced concrete structures based on BOFDA and FBG sensors, Shock and Vibration, pp. 2018 (2018).

12. K. S. C. Kuang, W. J. Cantwell and C. Thomas, Crack detection and vertical deflection monitoring in concrete beams using plastic optical fibre sensors, Measurement Science and Technology, Vol. 14, No. 2, pp. 205, (2003).

13. A. Mohan, S. Poobal, Crack detection using image processing: A critical review and analysis, Alexandria Engineering Journal, Vol. 57, No. 2, pp. 787-798, (2018).

14. V. Giurgiutiu and G. Santoni-Bottai, Structural health monitoring of composite structures with piezoelectricwafer active sensors, AIAA journal, Vol. 49, No. 3, pp. 565-581, (2011).

15. Y. Yang, B. S. Divsholi and C. K. Soh, A reusable PZT transducer for monitoring initial hydration and structural health of concrete, Sensors, Vol. 10, No. 5, pp. 5193-5208, (2010).

16. F. G. Baptista, D. E. Budoya, V. A. De Almeida and J. A. C. Ulson, An experimental study on the effect of temperature on piezoelectric sensors for impedancebased structural health monitoring. Sensors, Vol. 14, No. 1, pp. 1208-1227, (2014).

17. G. Park, H. H. Cudney and D. J. Inman, Feasibility of using impedance-based damage assessment for pipeline structures. Earthquake engineering \& structural dynamics, Vol. 30, No. 10, pp. 1463-1474, (2001).

18. R. Shanker, S. Bhalla, A. Gupta and M. Praveen Kumar, Dual use of PZT patches as sensors in global dynamic and local electromechanical impedance techniques for structural health monitoring, Journal of Intelligent Material Systems and Structures, Vol. 22, No. 16, pp. 1841-1856, (2011).

19. V. De Almeida, F. Baptista, L. Mendes and D. Budoya, Experimental analysis of piezoelectric transducers for impedance-based structural health monitoring, International Electronic Conference on sensors and applications, (2014).

20. S. Bhalla and C. K. Soh, Electromechanical impedance modeling for adhesively bonded piezotransducers, Journal of intelligent material systems and structures, Vol. 15, No. 12, pp. 955-972, (2004).

21. G. Park, C. R. Farrar, A. C. Rutherford and A.N. Robertson, Piezoelectric active sensor self-diagnostics using electrical admittance measurements, pp. 469476, (2006).

22. W. S. Hwang and H. C. Park, Finite element modeling of piezoelectric sensors and actuators, AIAA journal, Vol. 31, No. 5, pp. 930-937, (1993).

23. A. Myers, M. A. Mahmud, A. Abdelgawad and K. Yelamarthi, Toward integrating structural health monitoring with Internet of Things (IoT), In 2016 IEEE International Conference on Electro Information Technology (EIT), IEEE, pp. 0438-0441, (2016).

24. T.Srinivas and M. Abinay Raj, Int. J. of Eng.and Adv. Tech. (IJEAT), ISSN: 2249 - 8958, Volume-8 Issue-6 (2019)

25. T.srinivas and P. Manoj Anand, Int. J. of Innov. Tech. and Explor. Eng.g (IJITEE), ISSN: 22783075, Volume-8 Issue-12 (2019)

26. T.Srinivas and G. Sukesh Reddy, Int. J. of Eng.and Adv. Tech. (IJEAT), ISSN: 2249 - 8958, Volume-9 Issue-1 (2019)

27. T.Srinivas and R. N. Koushik, Int. J. of Innov. Tech. and Explor. Eng.g (IJITEE), ISSN: 22783075, Volume-8 Issue-12 (2019), PP 112-117.

28. K. Sai Gopi, Dr. T. Srinivas and S. P. Raju V, E3S Web of Conferences ICMED 184, 01084GRIET, 28-29 February, https://doi.org/10.1051/e3sconf/2020184011084( 2020)

29. Jagannadha Kumar, M.V., Jagannadha Rao, K., Dean Kumar, B., Srinivasa Reddy, V., Int. J. of Civil Eng. and Tech., 9(7), pp. 1133-1141 (2018)

30. Ganta, J.K., Seshagiri Rao, M.V., Mousavi, S.S., Srinivasa Reddy, V., Bhojaraju, C., Structures 28, pp. 956-972 (2020)

31. Naidu, K.S.S.T., Rao, M.V.S., Reddy, V.S., Int. J. of Innov. Tech. and Explor. Eng.g (IJITEE), 8(9 Special Issue 2), pp. 641-642 (2019)

32. Chandana Priya, C., Seshagiri Rao, M.V., Srinivasa Reddy, V., Int. J. of Civil Eng. and Tech., 9(11), pp. 2218-2225 (2018)

33. Satya Sai Trimurty Naidu, K., Seshagiri Rao, M.V., Srinivasa Reddy, V., Int. J. of Civil Eng. 
and Tech., 9(11), pp. 2383-2393 (2018)

34. Supriya, Y., Srinivasa Reddy, V., Seshagiri Rao, M.V., Shrihari, S., Int. J. of Rec. Tech. and Engi., 8(3), pp. 5381-5385 (2019)

35. Kotkunde, N., Krishna, G., Shenoy, S.K., Gupta, A.K., Singh, S.K. International Journal of Material Forming, 10 (2), pp. 255-266 (2017)

36. Govardhan, D., Kumar, A.C.S., Murti, K.G.K., Madhusudhan Reddy, G. Materials and Design, 36, pp. 206-214. (2012)

37. Kumar, P., Singhal, A., Mehta, S., Mittal, A. Journal of Real-Time Image Processing, 11 (1), pp. 93-109. (2016)

38. Raghunadha Reddy, T., Vishnu Vardhan, B., Vijayapal Reddy, P. International Journal of Applied Engineering Research, 11 (5), pp. 30923102 (2016)

39. Hussaini, S.M., Krishna, G., Gupta, A.K., Singh, S.K. Journal of Manufacturing Processes, 18, pp. 151-158 (2015) 